\title{
A questão do método nos estudos literários
}

\author{
The issue of method in the literary studies \\ Roberto Acízelo de Souza \\ Universidade do Estado do Rio de Janeiro - Rio de Janeiro - Rio de Janeiro - Brasil
}

$\diamond$

\begin{abstract}
Resumo: $\mathrm{O}$ artigo parte de uma definição geral de método na atividade científica, para depois concentrar-se na fisionomia específica de que se reveste o conceito no campo dos estudos literários. Defende a tese de que, embora um tanto secundarizada na agenda atual dos estudos literários, a questão do método é incontornável no processo da pesquisa, sendo pois indispensável que se lhe conceda atenção reflexiva.
\end{abstract}

Palavras-chave: Metodologia; Pluralismo e monismo metodológico; Metodofobia; Metodofilia

\begin{abstract}
This paper begins with a general definition of method in scientific activity, and then focus on the specific features the concept assumes in the field of literary studies. It defends the thesis that, in despite of its secondary position in the current agenda of literary studies, the issue of method is crucial in the research process, and therefore it is essential to grant it reflexive attention.
\end{abstract}

Keywords: Methodology; Methodological pluralism and monism; Methodophobia; Methodophilia

1

Por diversos motivos que esperamos se explicitem no curso da exposição que se segue, não se pode dizer que problemas de método e metodologia se encontrem em alta nos estudos literários hoje, havendo, muito ao contrário, pouco ou nenhum interesse em tais questões. No entanto, ao mesmo tempo, parece fora de dúvida que, em alguns momentos de suas práticas acadêmicas, os especialistas da área terão necessidade de pronunciarse sobre as diretrizes gerais e específicas que orientam suas reflexões, ou seja, terão de dar alguma satisfação sobre o(s) método(s) de sua eleição. Que mais não seja, nessa época de forte institucionalização da docência e da pesquisa universitárias, ainda que de maneira meramente protocolar, será incontornável dizer algo sobre a metodologia, numa tese de doutorado, por exemplo, ou, num projeto de pesquisa, na cabulosa seção dos "Fundamentos metodológicos e teóricos", que, como sabemos, sempre se recomenda incluir nos projetos.

Assim sendo, ou pela mera razão prática referida, ou, de modo mais decisivo, exatamente pelo caráter secundário atribuído à questão do método na agenda da área atualmente hegemônica - no pressuposto de que hegemonias devem sempre ser confrontadas por contrastes críticos -, julgamos muito oportuno e necessário abrir um espaço para considerações metodológicas referenciadas aos estudos literários.

\section{2}

Comecemos consignando uma suposição: parece que a preocupação com o método só se torna central a partir do século XVII, isto é, na conjuntura que deflagraria a modernidade, sendo emblemáticos, nesse sentido, Bacon, com o Novum organum (1620), e Descartes, com o Discurso do método (1637), matrizes respectivamente do empirismo e do racionalismo, esteios da moderna concepção de método. O problema, a partir de então, ganha tal relevo que chega a extrapolar sua condição inicial de simples ferramenta para a atividade filosófica e científica, ganhando importância intrínseca, a ponto de tornar-se objeto de uma disciplina, a metodologia. Sintoma de que, já no século XVIII, o método era quase uma obsessão encontramos num pronunciamento de Kant, na Crítica da razão pura (1781), em que o filósofo propõe certa relativização da relevância do método no trabalho intelectual, especialmente no âmbito da filosofia: 
Na Filosofia não se deve imitar a Matemática no que tange a iniciar com as definições, a não ser que assim se proceda a título de mera tentativa. [...] na Filosofia, a definição, enquanto uma clareza precisa, deve antes concluir do que iniciar o nosso labor (KANT, 1980 [1781], p. 359-360).

A Filosofia formiga de definições defeituosas, sobretudo de tais que na verdade contêm efetivamente elementos para a definição, mas não de modo completo. Ora, se não se pudesse fazer absolutamente nada com um conceito antes que tivesse sido definido, então as coisas andariam bastante mal para todo o filosofar. [...] as definições deficientes, isto é, proposições que propriamente não são ainda definições, mas de resto são verdadeiras e portanto aproximadas delas, podem ser usadas muito utilmente. Na Matemática a definição concerne ad esse, na filosofia ad melius esse. É belo, mas frequentemente muito difícil, chegar a isto. Os juristas ainda procuram uma definição para o seu conceito de direito (KANT, 1980 [1781], p. 360).

E Kant de fato foi consequente com essa ideia de não condicionar a reflexão filosófica a uma espécie de tutela metodológica que, no limite, poderia até inviabilizá-la; assim, na arquitetura da primeira Crítica (1781), depois de uma introdução relativamente sumária, não por acaso reserva o primeiro e mais espaçoso compartimento à "Doutrina transcendental dos elementos", relegando ao segundo a "Doutrina transcendental do método", a que, de resto, confere um desenvolvimento quase tão sumário quanto o da introdução.

Mas, não obstante a moderação kantiana no manejo da noção de método, não há dúvidas de que ela se imporia de modo absorvente, e talvez tenha conhecido o auge do seu prestígio no século XIX e primeira metade do XX. Não deixou, contudo, de suscitar reações, representadas, por exemplo, pela pregação de Paul Feyerabend, sistematizada sobretudo no seu Contra o método (1975), bem como, mais recentemente, pela defesa empreendida por Edgar Morin do que ele chama "antimétodo", num prolixo tratado aliás intitulado $O$ método, por uma espécie de ironia involuntária. Vejamos uma passagem de cada autor, para ilustrar a posição por eles assumida:

A ciência é um empreendimento essencialmente anárquico: o anarquismo teorético é mais humanitário e mais suscetível de estimular o progresso do que as alternativas representadas por ordem e lei (FEYERABEND, 1989 [1975], p. 17).

A incerteza torna-se um viático: a dúvida sobre a dúvida dá à dúvida uma dimensão nova, a dimensão da reflexividade; a dúvida pela qual o sujeito se interroga sobre as condições de emergência e de existência do seu próprio pensamento constitui [...] um pensamento potencialmente relativista, relacionista e autocognoscente. Enfim, a aceitação da confusão pode tornar-se um modo de resistir à simplificação mutiladora. É certo que nos falta o método à partida; mas, pelo menos, podemos dispor do antimétodo, onde a ignorância, a incerteza e a confusão se tornam virtudes (MORIN, 1997-2005 [1977-2004], p. 19, v. 1).

\section{3}

Apesar de tais reservas, contudo, a indagação sobre o método fez carreira. Chegou, como dissemos, a instaurar um espaço disciplinar próprio, dito metodologia, e cujo âmbito pode ser segmentado em quatro níveis.

Num nível primário, a metodologia consiste na sistematização de técnicas básicas de estudo e preparação de trabalhos acadêmicos, situando-se no espaço da pedagogia. Num segundo nível, trata da caracterização de procedimentos e estratégias especializadas visando à constituição, descrição e análise de objetos próprios de disciplinas específicas, e nesse caso se insere no âmbito da disciplina em questão. Num nível terciário, constitui-se como reflexão sobre o conhecimento produzido em determinada área, ocupando-se com seus critérios de validade e modos de integração, bem como com aspectos técnicos e éticos da atuação profissional de seus especialistas, e como tal tanto se caracteriza como epistemologia regional (BUNGE, 1987 [1980], p. 16-17) quanto se inscreve na órbita da sociologia do conhecimento. Por fim, num quarto nível, se estabelece como reflexão sobre o processo de elaboração do conhecimento científico em geral, considerando seus condicionamentos internos e externos, e assim alcançando o status de epistemologia geral ou filosofia das ciências.

Nosso interesse, aqui, exclui apenas o primeiro nível, e assim propomo-nos, transitando pelos três outros, analisar alguns aspectos do problema metodológico na sua referência aos estudos literários.

\section{4}

Convém iniciar pela definição de método, que, como os conceitos filosóficos em geral, não se resolve numa fórmula consensual, comportando, ao contrário, várias alternativas. Segundo uma delas, frequentemente citada, método se define como caminho para um fim. Trata-se de uma definição por assim dizer poéticoetimológica, que pode ter algum encanto, mas pouca ou nenhuma consequência conceitual. Vejamos, então, algumas definições mais técnicas, potencialmente mais interessantes para a exploração que pretendemos fazer do conceito.

Método é o conjunto dos princípios orientadores de uma pesquisa científica, segundo uma delas. Conforme 
outra, consiste em certa perspectiva ou centro de interesse a partir do qual se investiga cientificamente determinada região da realidade. Uma terceira, por seu turno, estabelece que constitui o método o conjunto de condições materiais, recursos instrumentais $e$ procedimentos técnicos para a execução de um estudo científico. Por fim, é usual encontrar-se ainda uma quarta definição, que o caracteriza como redução de uma teoria à sua aplicação a casos particulares.

Abandonemos agora a compreensão poéticoetimológica, dada sua intransitividade, e retenhamos tão somente as definições propriamente ditas. Se abstrairmos suas diferenças secundárias, atentando para o que têm em comum - a conexão com as noções correlatas de ciência, teoria e técnica -, podemos perceber duas concepções básicas de método, respectivamente chamadas monista e pluralista (BUNGE, 1976 [1969], p. 47). Segundo a primeira, o método é comum a todas as ciências, consistindo numa sequência invariável de procedimentos: observação, experimentação, quantificação, dedução matemática. Dentro dessa unidade, será hipotéticoindutivo, caso o ponto de partida seja a observação, ou axiomático-dedutivo, caso seja a dedução matemática. Conforme a segunda, ao contrário, em vez de se prestarem a classificação econômica, os métodos se revelam muito diversificados, pois variam de acordo com a especificidade da perspectiva ou centro de interesse cognitivo em questão, e assim, no limite, haverá tantos métodos quantos são as disciplinas.

\section{5}

Façamos agora uma pausa para exemplificação.

Seja o dado "dentes humanos". Ora, estudá-lo cientificamente implica fazer observações, desenvolver experiências, quantificar resultados, estabelecer deduções; em síntese, aplicar o método. Mas esse dado pode ser investigado, por exemplo, como um dos componentes morfológicos do corpo, como um dos intervenientes na digestão, como um subconjunto integrado de funções orgânicas, ou seja, respectivamente, na perspectiva da anatomia, da gastroenterologia, da odontologia, isto é, segundo os métodos anatômico, gastroenterológico, odontológico.

Como logo se percebe, o equacionamento acima se fez com base na concepção pluralista antes referida, segundo a qual método constitui noção correlata de perspectiva ou centro de interesse, operadores aptos a transformar dados em objetos, assim configurando um campo especializado de conhecimento, ou seja, uma disciplina. Tentando esclarecer melhor, e atentos ainda ao nosso exemplo: "dentes humanos" constitui um simples dado, e como tal um elemento da realidade disponível à apreensão segundo diversos interesses. Se nos aproximamos desse elemento interessados em conhecê-lo na condição de um componente morfológico do corpo, então nos apropriamos dele a partir de um interesse anatômico, e desse modo servimo-nos do método da anatomia e convertemos o dado em objeto dessa ciência, o que significa dizer que nos colocamos no seu espaço disciplinar. Fosse o nosso interesse conhecer o dado "dentes humanos" sob outra ótica - digamos, a da odontologia -, nesse caso o método a ser utilizado seria outro, e, pois, o objeto também, e do mesmo modo a disciplina.

A partir dessas considerações podemos fazer três inferências.

A primeira é que, adotada a concepção pluralista, torna-se evidente uma relação de implicação recíproca entre as noções de método, objeto e disciplina, que assim podemos representar: método $\leftrightarrow$ objeto $\leftrightarrow$ disciplina.

A segunda é que a concepção monista - o método científico é um só para todas as disciplinas -, se parece adequada para as ciências exatas e as da natureza, não o é para as humanas, em cujo âmbito seria difícil vislumbrar, numa situação concreta de pesquisa que se viesse a analisar, a observância sequencial das instâncias de observação, experimentação, quantificação e dedução matemática. Pois como cumprir, numa investigação filosófica, por exemplo, o momento da quantificação? Convenhamos que, quando isso for possível, estaremos antes em face de exceção do que da regra.

Por outro lado, em compensação - e eis a terceira inferência -, parece que as chamadas ciências duras não se revelam muito compatíveis com a concepção pluralista. Basta verificar, nesse sentido, como soam estranhas as expressões método anatômico, método gastroenterológico, método odontológico, por nós utilizadas acima por necessidade argumentativa, as quais, como vimos, implicam postular especificações disciplinares do método; em contrapartida, método histórico, método sociológico, método linguístico etc. são locuções que podemos empregar sem qualquer abalo nos sensores ultrassensíveis dos usos idiomáticos.

\section{6}

Fechemos agora, enfim, o foco sobre os estudos literários.

É fato incontroverso que a teoria da literatura, a mais típica representação disciplinar da área no século $\mathrm{XX}$, nasceu sob o signo da discussão metodológica. Como sabemos, o tratado fundador da disciplina - o influente Teoria da literatura, de René Wellek e Austin Warren, publicado em 1949 -, se estruturou justamente 
tendo em vista a questão do método. ${ }^{1}$ Assim, propôs uma classificação seminal, ao fazer distinção entre o que chamaram os autores "métodos extrínsecos" e "estudo intrínseco da literatura", este voltado para a análise crítica da obra considerada em si mesma, como artefato verbal autônomo e de natureza estética, e aqueles dirigidos aos seus aspectos tidos por periféricos, e por sua vez divididos em quatro modalidades: métodos biográfico, psicológico, sociológico e filosófico. Essa constituiu a tese defendida no tratado, bem como o princípio ordenador de suas partes e capítulos, o que dá bem a medida da centralidade assumida pelo problema do método na sua concepção.

Duas décadas depois, o problema continuava na agenda da área, do que é indício obra de alguma presença internacional de autoria do professor argentino Enrique Anderson Imbert. ${ }^{2}$ Trata-se de Métodos de crítica literária (1969), em que o autor, nitidamente ecoando a sistematização proposta por Wellek e Warren, apresentava uma classificação bastante minuciosa dos métodos utilizáveis nos estudos literários, porém não menos confusa, além de afetada por diversas inconsistências. Em síntese, e não cabendo aqui discutir o mérito da proposição, ele parte da distinção entre o que chama "métodos auxiliares" ou da "crítica externa" - que comportariam os métodos histórico, sociológico e linguístico, além de outros que o autor contempla com um "etc." - e "métodos da crítica interna". Estes, por sua vez, se diversificariam em várias modalidades, ordenadas em três categorias básicas: métodos da "atividade criadora", desdobrados nos métodos histórico, sociológico e psicológico; da "obra criada", constituídos pelos métodos temático, formalista e estilístico; e métodos da "recriação do leitor", subdivididos nos métodos dogmático, impressionista e revisionista.

Pela mesma época, no âmbito do estruturalismo neoformalista francês, Tzvetan Todorov dedica considerável atenção ao problema do método, num dos ensaios integrantes do volume $O$ que é o estruturalismo? (1968), destinado a apresentar a nova fisionomia assumida por diversas disciplinas pela adoção dos pressupostos estruturalistas. No referido ensaio, publicado no Brasil num pequeno volume autônomo intitulado Estrutura-

\footnotetext{
1 Assinale-se que, como declaram os autores no prefácio à primeira edição da obra (1962 [1949], p. 9), o título de que cogitaram inicialmente para o livro foi Teoria da literatura e metodologia do estudo literário, enfim preterido pela formulação mais econômica Teoria da literatura. Há duas traduções da obra para o português: a portuguesa, de 1962, conserva o título do original inglês; a brasileira, de 2003, recupera o título primeiramente cogitado pelos autores, apenas pluralizando a expressão nele constante "literary study", traduzida por "estudos literários".

2 Na verdade, modalizando um pouco a asserção, parece restrita a circulação internacional da obra, pois, escrita em espanhol, que seja do nosso conhecimento só logrou tradução para o português. Seu autor, contudo, tendo sido professor nas Universidades de Columbia e de Michigan, regeu por longos anos, de 1965 até se aposentar em 1980, a cátedra de literatura hispano-americana em Harvard, criada especialmente para ele.
}

lismo e poética (1970), a questão do método é tratada na seguinte passagem:

[...] o objeto da Poética é a literatura, ou [...] a literariedade; e seu método, as leis que lhe governam o discurso. Mas se examinarmos de mais perto essas duas noções, a evidência cede lugar a uma incerteza. [...] toda obra de Poética [...] trata de literatura, mas através dela trata, e isso a um nível mais profundo, de seu próprio discurso, da imagem da literatura que ele propõe. O fim último de tal obra é sempre a construção de uma teoria; seria mais exato e mais honesto dizer que o fim da obra científica não é o melhor conhecimento de seu objeto, mas o aperfeiçoamento do discurso científico. Trata-se de uma consequência do caráter teórico desse tipo de discurso. Mesmo que as obras concretas fossem o objeto da Poética, na medida em que seu discurso é teórico, ela substituiria imperceptivelmente esse objeto pelo seu próprio discurso. Mas como a Poética só trata de virtuais, não de reais, e como esses virtuais existem precisamente pela força de seu discurso, parece incontestável que seu objeto primeiro não é senão um meio de tratar do segundo. [...] a Ciência não fala do seu objeto, mas fala de si com a ajuda desse objeto.

Produz-se, portanto, uma curiosa inversão: o objeto da Poética é precisamente seu método; [...] as discussões metodológicas não s[ão] uma parte limitada do conjunto da Ciência, uma espécie de produto suplementar, mas lhe s[ão] o próprio centro. Quanto à literatura, ela é precisamente a linguagem que permite à Poética voltarse para si mesma, a mediadora de que esta se utiliza para conhecer-se a si própria. [...] esse objeto aparente que é a literatura não passa [...] de um método particular escolhido por um discurso para tratar de si próprio. $\mathrm{O}$ método é o objeto da Ciência, e seu objeto seu método (TODOROV, 1970 [1968], p. 117-118).

A citação decerto saiu mais longa do que o desejável, mas não nos pareceu possível submeter a passagem a cortes ou parafraseá-la, sem que se perdesse o que tem de fundamental. Não sendo aqui pertinente discutir os muitos problemas que suscita, considerando os objetivos que nos propusemos, basta pôr em relevo a habilidosa manobra argumentativa do autor, com a qual, aliás, ele próprio parece deslumbrar-se, ao defini-la como "curiosa inversão". Mediante a manobra referida, ele rompe o compromisso das ciências com o que seria um trambolho grosseiro - seus objetos -, e, por "curiosa inversão", substitui estes pela finura dos métodos, com isso tornando a operação do conhecimento uma espécie de trânsito livre por uma estrada desimpedida, que, de resto, numa circularidade confortável, conduziria da ciência à própria ciência. No caso específico da poética, então, é esquecer essa coisa informe e fugidia - a literatura -, a fim de lidar apenas com o próprio método forjado para se conhecer a literatura. 
Estranha opção por absoluta segurança operacional, vale dizer, metodológica: exorciza-se assim qualquer possibilidade de inconsistências, erros ou contradições, mas, como parece correto constatar, à custa de uma estéril tautologia. No entanto, como a crítica desses aspectos nos dispersaria de nosso tema, concentremo-nos no que por ora nos interessa: talvez tenhamos aqui a mais completa defesa do relevo que se deveria dar à metodologia no âmbito dos estudos literários, cristalizada em verdadeira proclamação: “[...] as discussões metodológicas não s[ão] uma parte limitada do conjunto da Ciência, uma espécie de produto suplementar, mas lhe s[ão] o próprio centro" (TODOROV, 1970 [1968], p. 117-118).

Logo, contudo, a questão como que refluiria, num verdadeiro recesso. Indício desse estado de coisas é o fato de que ela não se faz presente, pelo menos de modo explícito e direto, em obras-síntese de teoria da literatura que se projetaram em décadas mais recentes. Para conferir, veja-se um título inglês, um francês e um norte-americano: Teoria da literatura: uma introdução, de Terry Eagleton (1983), O demônio da teoria: literatura e senso comum, de Antoine Compagnon (1998), e Teoria literária: uma introdução, de Jonathan Culler (1999).

\section{7}

E hoje: que panorama se apresenta, nos estudos literários, quanto à reflexão metodológica?

Diríamos que, na atualidade, existem duas posições a propósito da questão: a uma delas, hegemônica, chamemos metodofobia; à outra, metodofilia.

O horror ao método, por sua vez, se manifesta sob dois aspectos: ora se impugna o método como reducionismo incompatível com a grandeza incomensurável da literatura, ora por seu compromisso com a compartimentalização do conhecimento, que deveria ser neutralizada pela adoção de perspectiva dita inter-, multi- ou transdisciplinar. No primeiro caso, configura-se a recusa humanística, ao passo que, no segundo, temos a recusa culturalista; por mais que a motivação de cada qual na aparência não se confunda com a outra, o fato é que há entre elas inesperadas coincidências, e, de resto, em ambas, a mesma metodofobia.

Quanto à metodofilia, trata-se de posição de resistência, que rejeita categoricamente fórmulas sensacionalistas e inconsequentes, de que constitui incrível exemplo a seguinte recomendação: "[...] podemos dispor do antimétodo, onde a ignorância, a incerteza e a confusão se tornam virtudes" (MORIN, 1997-2005, p. 19, v. 1). Em troca, a posição de afeição pelo método articula alguns princípios-chave: reconhece a necessidade incontornável de enfrentamento explícito da questão metodológica, inclusive por não perder de vista que os estudos literários constituem, por definição, área particularmente sujeita aos chamados "juízos de gosto" (KANT, 1974 [1790]), que, fora de um estrito controle conceitual - e, pois, metodológico -, podem tornar-se álibi para interpretações arbitrárias e infensas a referendo intersubjetivo; considera pertinente e legítima a demanda pelo "método próprio", ou o empenho por aproximações graduais a métodos que se revelem crescentemente menos impróprios; e, ciente da correlatividade entre as noções de método e disciplina, defende a disciplinaridade, contra a complacência dos arranjos interdisciplinares e congêneres.

\section{8}

Para concluir, uma última observação:

No ano de 1975, no contexto do seu Contra o método, Paul Feyerabend fazia a seguinte concessão ao racionalismo, objeto de seu violento e competente ataque ao longo da obra:

Poderá, é claro, vir tempo em que se faça necessário conceder à razão uma vantagem temporária e em que será avisado defender suas regras, afastando tudo o mais. Não creio, porém, que estejamos vivendo esse tempo (FEYERABEND, 1989 [1975], p. 23).

Não podemos saber se o autor, considerando o atual estado do mundo, acharia que esse tempo tivesse chegado. ${ }^{3}$ De nossa parte, não temos dúvida de que chegou, e, de resto, não nos parece acertado que se conceda à razão, em 1975, hoje ou em qualquer outra quadra da história, apenas uma "vantagem temporária".

\section{Referências}

ANDERSON IMBERT, Enrique. Métodos da crítica literária. Tradução de Eugénia Maria M. Madeira Aguiar e Silva. Coimbra: Almedina, 1971 [1969].

ASTI VERA, Armando. Metodologia da pesquisa científica. Tradução de Maria Helena Guedes Crespo e Beatriz Marques Magalhães. Porto Alegre: Globo, 1973 [1968].

BACON, Francis. Novum organum: ou verdadeiras indicações acerca da interpretação da natureza [1620]. In: BACON, Francis. Novum organum: ou verdadeiras indicações acerca da interpretação da natureza/Nova Atlândida. Tradução e notas de José Aluysio Reis de Andrade. São Paulo: Abril Cultural, 1979. p. 1-231.

BUNGE, Mario. La investigación cientifica: su estrategia y su filosofía. Traducción castellana de Manuel Sacristán. Barcelona: Ariel, 1976 [1969].

BUNGE, Mario. La ciência: su método y su filosofía. Buenos Aires: Siglo Veinte, 1977 [1960].

\footnotetext{
Tendo construído uma carreira acadêmica exitosa, como professor em diversas universidades importantes de vários países, Paul Feyerabend morreu em 1994
} 
BUNGE, Mario. Epistemologia: curso de atualização. Tradução de Cláudio Navarra. São Paulo: T. A. Queiroz, 1987 [1980].

COMPAGNON, Antoine. O demônio da teoria: literatura e senso comum. Tradução de Cleonice Paes Barreto Mourão. Belo Horizonte: Ed. da UFMG, 1999 [1998].

CULLER, Jonathan. Teoria literária: uma introdução. Tradução de Sandra Guardini T. Vasconcelos. São Paulo: Becca, 1999.

DESCARTES, René. Discurso do método: para bem conduzir a própria razão e procurar a verdade nas ciências [1637]. In: DESCARTES, René. Discurso do método/Meditações/ Objeções e respostas/As paixões da alma/Cartas. Introdução de Gilles-Gaston Granger. Prefácio e notas de Gérard Lebrun. Tradução de J. Guinsburg e Bento Prado Júnior. São Paulo: Abril Cultura, 1979. p. 25-71.

EAGLETON, Terry. Teoria da literatura: uma introdução. Tradução de Waltensir Dutra. São Paulo: Martins Fontes, 2003 [1983].

FERRATER MORA, José. Método. In: FERRATER MORA, José. Diccionario de filosofía. Buenos Aires: Sudamericana, 1971 [1941]. v. 2, p. 197-200.

FEYERABEND, Paul. Contra o método: esboço de uma teoria anárquica da teoria do conhecimento. Tradução de Octanny S. da Mota e Leonidas Hegenberg. Rio de Janeiro: Francisco Alves, 1989 [1975].

KANT, Immanuel. Crítica da razão pura: e outros textos filosóficos. Seleção de Marilena de Souza Chauí Berlinck.
Tradução de Valério Rohden, Paulo Quintela, Rubens Rodrigues Torres Filho e Tânia Maria Bernkopf. São Paulo: Abril, 1974 [1781/1783/1785/1790/1793].

KANT, Immanuel. Crítica da razão pura. Tradução de Valério Rohden e Udo Baldur Moosburger. Apresentação de Valério Rohden. Consultoria de Marilena Chauí. São Paulo: Abril Cultural, 1980 [1781].

MAGALHÃES, Gildo. Introdução à metodologia da pesquisa: caminhos da ciência e tecnologia. São Paulo: Ática, 2005.

MORIN, Edgar. O método. Tradução de Maria Gabriela de Bragança, Emílio Campos Lima e J. Espadeiro Martins. Mem Martins: Europa-América, 1997-2005 [1977-2004]. 6 v.

SALOMON, Délcio Vieira. Como fazer uma monografia. Belo Horizonte: Interlivros, 1972.

TODOROV, Tzvetan. Estruturalismo e poética. Tradução de José Paulo Paes. São Paulo: Cultrix, 1970 [1968].

WELLEK, René; WARREN, Austin. Teoria da literatura. Tradução de José Palla e Carmo. Lisboa: Europa-América, 1962 [1949].

WELLEK, René; WARREN, Austin. Teoria da literatura e metodologia dos estudos literários. Tradução de Luiz Carlos Borges. São Paulo: Martins Fontes, 2003 [1949].

Recebido: 29 de abril de 2014

Aprovado: 08 de junho de 2014

Contato: acizelo@bighost.com.br 